\title{
Contribuiçóes da Clínica da Parentalidade NO ATENDIMENTO DE UM CASO DE OBESIDADE INFANTIL
}

\author{
Contributions of the Clinic of PARENTALITy in the \\ PSYCHOLOGICAL TREATMENT OF A CHILD OBESITY CASE \\ ContribuCiones DE LA CLÍNICA DE LA \\ PARENTALIDAD EN UN CASO DE OBESIDAD INFANTIL ${ }^{1}$
}

\author{
Nathalia T. C. Campana* \\ Isabel C. Gomes** \\ Rogério Lerner***
}

\section{RESUMO}

Estudos a respeito da obesidade indicam que, para além de questóes genéticas, seu surgimento pode estar associado às primeiras relaçóes interpessoais. $\mathrm{O}$ presente artigo tem como objetivo discutir as contribuiçóes que a clínica da parentalidade pode trazer para o tratamento da obesidade infantil a partir de recortes de um caso clínico. Para tanto, será apresentado o conceito de parentalidade, sua derivação clínica e questôes da contemporaneidade que interferem no processo de se tornar pai e mãe. A interpretação do material clínico revelou que o comportamento de comer compulsivo da criança estava relacionado à fragilização parental, em acordo com os dados da literatura. Assim, trabalhar no contexto da clínica da parentalidade pode favorecer a melhora do sintoma na medida em que liberta a criança de um legado inenarrável e fortalece tanto o lugar subjetivo da criança quanto as funçóes parentais. Além disso, nos casos necessários, pode contribuir para a construção de uma demanda para terapia familiar.

Palavras-chave: obesidade infantil; parentalidade; família; psicanálise.

* Universidade de São Paulo, São Paulo, SP, Brasil.

** Universidade de São Paulo, São Paulo, SP, Brasil.

*** Universidade de São Paulo, São Paulo, SP, Brasil. 


\section{Abstract}

Studies about obesity show that, in addition to possible genetic constitution, its appearance may be associated with early interpersonal relationships. This paper aims to discuss, through clips of a clinical case, contributions that the clinic of parentality may have for the treatment of infantile obesity. For this purpose, the concept of parentality, its clinical derivation and issues related to contemporaneity which interfere in the process of becoming a mother and a father will be introduced. The interpretation of the clinical material revealed that the child behavior of eating compulsively was related to parental fragility, according to the scientific literature. Thus, working in the context of the clinic of parentality may favor relieving of the symptom as it releases the child of an unspeakable legacy and strengthens its subjective position and parental functions. Furthermore, when necessary, it's possible to contribute for bringing up a demand for family therapy.

Keywords: obesity in children; parentality; family; psychoanalysis.

\section{RESUMEN}

Estudios con respeto a la obesidad indican que, además de cuestiones genéticas, su surgimiento puede estar asociado a las primeras relaciones interpersonales. El presente artículo tiene por objetivo discutir las contribuciones que la clínica de la parentalidad puede traer para el tratamiento de la obesidad infantil, a partir de recortes de un caso clínico. Para tanto, será presentado el concepto de parentalidad, su derivación clínica y cuestiones de la contemporaneidad que interfieren en el proceso de tornarse padre y madre. La interpretación del material clínico reveló que el comportamiento de comer compulsivo del niño estaba relacionado a la fragilidad parental, de acuerdo con los datos de la literatura. Así, trabajar en el contexto de la clínica de la parentalidad puede favorecer la mejora del síntoma en la medida en que liberta el niño de un legado inenarrable y fortalece tanto el lugar subjetivo del niño como las funciones parentales. Además, en los casos en que es necesario, pueden contribuir para la construcción de una demanda para terapia familiar.

Palabras clave: obesidad infantil; parentalidad; familia; psicoanálisis.

\section{Introdução}

Este artigo é resultado de um estudo qualitativo a respeito das contribuiçôes que a clínica da parentalidade pode trazer para o atendimento de crianças 
obesas. Para isso enfocaremos tanto a conceituação desse tipo de clínica quanto autores que abordam a questão da obesidade na perspectiva psicanalítica. Em seguida, apresentaremos recortes de um caso clínico como forma de promover uma reflexão teórico-clínica sobre o tema.

O avanço de estudos sobre a vida emocional dos bebês e a experiência clínica com crianças e adolescentes evidenciaram a importância de considerar os pais no atendimento de seus filhos, fazendo surgir a expressão parentalidade. A definição desse conceito abrange três aspectos fundamentais: a função parental, a noçáo de parentesco e a história de origem do indivíduo e das geraçóes que o sucederam. Nesse sentido, Solis-Ponton e Lebovici (2004) destacam que a parentalidade vai além de fatores biológicos e que para se tornar pai ou mãe é necessário um trabalho interior que começa pela aceitação de que herdamos algo de nossos pais.

Da Silva (2011) define a parentalidade como um conjunto de processos psicoafetivos que se desenvolvem e se integram nos pais, ou seja, se refere ao aspecto dinâmico e processual da experiência de se tornar pai e mãe. Nas palavras da autora "O estudo da parentalidade refere-se aos laços parentais, aos vínculos afetivos que se estabelecem muito precocemente entre pais e filhos e que são o umbral a partir do qual se constrói o processo de subjetivação, a vida psíquica do bebê" (Da Silva, 2011, p. 26). Desta forma, a clínica da parentalidade propóe intervenções na relação pais-bebê-criança que levem em conta a construção das funções materna e paterna, o vínculo que os pais estabelecem entre si, com o filho e a história da família. Por meio da investigação das fantasias transgeracionais, busca-se retirar a criança dos investimentos inconscientes nela depositados pelos pais e favorecer a elaboraçáo de conflitos relacionados à parentalidade. Para isso, as contribuiçóes de Winnicott a respeito do amadurecimento humano e a teoria do apego desenvolvida por Bowlby são de grande valia. É no aqui-agora das sessões, na interação dos pais em suas funções parentais com os filhos, que se procura fortalecer a parentalidade e o lugar subjetivo da criança. É comum que esse modelo de atendimento seja mais eficaz no caso de crianças pequenas, pois se entende que os conflitos ainda não estão cristalizados.

A parentalidade, como abordagem metodológica, toma como fio condutor a exploração da árvore da vida, assim como a narração que se constrói no momento da consulta; vinda da intersubjetividade para o trabalho entre os membros do grupo familiar e terapêutico, pode facilitar um remanejamento metaforizante das ligaçóes familiares, residindo aí seu valor terapêutico (Solis-Ponton \& Gutfreind, 2004, p. 77). 
No processo de construção da parentalidade, a criança é ativa e age sobre os pais, esforçando-se para parentalizá-los e, assim, assumirem sua função. $\mathrm{O}$ nascimento de um bebê atualiza questóes referentes ao modelo familiar de origem dos pais e a criança é inserida em uma cadeia de desejos, expectativas e fantasias. Segundo Corso e Corso (2009), "viver é continuar uma história, que faz parte da história de alguém que veio antes, de um tempo, de um grupo, de uma época, de tal modo que estamos sempre lidando com restos, troféus e assombraçóes do passado" (Corso \& Corso, 2009, p. 13). A esse respeito, Kaës (2011) propóe pensar a organização do espaço psíquico comum e partilhado, afirmando que a subjetivaçáo passa por um duplo processo psíquico que abarca tanto o trabalho de cada sujeito, segundo seus determinantes internos, quanto outro que se desenvolve a partir do espaço psíquico intersubjetivo. Assim, a formação do eu obedece ao mesmo tempo à sujeição de um lugar que está marcado de antemão e à necessidade de distanciar-se desse lugar prescrito.

$\mathrm{Na}$ teoria winnicottiana, as capacidades inatas do bebê precisam ser exercidas no contexto de cuidados facilitadores, integrando os aspectos do self. Assim, a capacidade para a experiência é uma conquista do amadurecimento que depende da facilitação ambiental e, por isso, embora ela seja possível, pode não ser alcançada plenamente. Os estudos de Bowlby (1969/2002) revelam a importância dos vínculos de apego para a formação do sujeito. Segundo o autor as relaçóes familiares se sustentam pelo apego, que se constitui como base essencial dos vínculos sociais, que unem as geraçôes sucessivas na espécie humana. Quando os pais contam suas próprias histórias, deixam os filhos livres para que possam construir suas narrativas (Gutfreind, 2009). Porém esse processo pode ser custoso para algumas famílias, especialmente quando os pais viveram histórias passadas mal elaboradas, portanto difíceis de serem postas em palavras. Nesse sentido, a oferta de um espaço terapêutico em que poderão narrar e ter suas historias recontadas se configura como possibilidade de criar algo novo, liberto de um legado inenarrável, recuperando ou engendrando a própria função de rêverie (Bion, 1962/1966).

$\mathrm{Na}$ contemporaneidade, novos fatores interferem no processo de construção da parentalidade. Dentre eles se destacam o declínio da função patriarcal e a fragilização parental. $\mathrm{O}$ primeiro ocorre devido a exigências socioculturais que demandam novos lugares a serem ocupados pelos indivíduos, levando pais e filhos a vivenciarem relaçóes igualitárias e fraternais (Gomes \& Levy, 2009). O segundo é resultado da desvalorização do saber dos pais em relação aos filhos frente ao conhecimento especializado, hipervalorizado atualmente (Zanetti \& Gomes, 2009). Como consequência desse movimento, os pais são movidos pela ilusão de não repetir os padrôes que receberam em suas famílias de origem e tendem a 
criar parâmetros idealizados a respeito de como educar a criança. E quando não podem dar aos filhos o que acham que eles precisam, acabam por se sentir em dívida para com eles. Essa dinâmica interfere nas relaçôes parentais porque mobiliza um funcionamento paralisante quanto ao medo do ressentimento dos filhos, e o princípio da autoridade é substituído por um posicionamento inadequado frente à culpa que acreditam ter (Zanetti \& Gomes, 2009). Quando os pais não têm referências claras de como educar os filhos, acabam por se tornar autoridades inconsistentes para as crianças.

Winnicott (1960/1999) enfatizava a importância de os pais estarem confiantes em si para poderem oferecer segurança a seus filhos:

Assim, no começo, a mãe, em breve ambos os pais, passam a incumbir-se da tarefa de impedir que coisas inesperadas aconteçam. Podem fazer isso deliberadamente, mas isso acontece principalmente quase que em seus próprios corpos; é todo um modo de comportamento que reflete uma atitude mental. $\mathrm{O}$ bebê sente-se seguro e absorve a confiança da mãe em si mesma, como se estivesse ingerindo o leite. ... Durante os bombardeiros aéreos, os bebês não tinham medo do estrondo das bombas, mas eram imediatamente afetados quando as mães estavam em pânico (Winnicott, 1960/1999, p. 44).

Dentre os sintomas infantis, a obesidade foi considerada pela OMS (2013) como um problema de saúde pública dos mais graves no século XXI, sobretudo em meios urbanos. Em 2010, havia 42 milhóes de crianças com sobrepeso em todo o mundo, dos quais 35 milhóes viviam em países em desenvolvimento. A maior parte das pesquisas aborda os aspectos genéticos e consequências para a saúde física e emocional das crianças, mas pouco se tem estudado a respeito dos fatores emocionais que podem contribuir para o surgimento do sintoma.

Mishima e Barbieri (2009) realizaram um estudo com o objetivo de compreender o funcionamento psicodinâmico de crianças obesas, salientando a ligação emocional entre mães e filhos. Os resultados apontam que essas crianças apresentavam dificuldade no processo criativo, comportamento de passividade, dependência, baixa autoestima, insegurança e sentimento de solidão. Neste contexto, a busca excessiva por alimento pode ser considerada sintoma de ansiedade, sugerindo dificuldades psíquicas, afetivas e relacionais. As autoras afirmam ainda que a raiz mais primitiva dessa dificuldade se encontra na fase que Winnicott denominou de dependência relativa - estágio da desilusão e início dos processos mentais. Miranda (2010) estabeleceu uma relação entre o comer compulsivo e as 
relaçóes primitivas. A autora discute que o comer pode ser visto como equivalente ao ato de restaurar o bom objeto e de tentativa do sujeito de se fortalecer. Nesta dinâmica, o alimento seria equivalente ao poder materno de nutrir com leite e com amor. Esses sujeitos estão restringidos em suas capacidades criativas e não há possibilidade de pensar a dor.

Partindo do pressuposto de que o sintoma de comer compulsivamente diz respeito a dificuldades no vínculo pais-criança e a questóes referentes à parentalidade, é pertinente que possamos pensar uma proposta de tratamento que considere não apenas a criança que manifesta o sintoma, mas também seus pais. O caso clínico que será apresentado a seguir foi atendido em um ambulatório de psicologia ligado a um hospital escola de referência na cidade de São Paulo.

\section{Caso clínico}

Bruna $^{2}$, de sete anos, compareceu para uma consulta ${ }^{3}$ no ambulatório de psicologia acompanhada de sua mãe Marta, de vinte e sete anos, que estava grávida de oito meses. A menina foi encaminhada pelo pediatra, pois comia compulsivamente e estava obesa. Além disso, apresentava dificuldade para aceitar a gestação de sua mãe e para se relacionar com o padrasto, com quem Marta estava casada há 10 meses. Tanto o pediatra quanto a nutricionista que se ocupavam do caso acreditavam que componentes emocionais estavam contribuindo para a dificuldade de emagrecimento da menina.

A primeira consulta foi marcada pelo relato de conteúdos geracionais. Marta contou sua própria história e disse ter medo que tudo se repetisse com a filha. Em sua família, foram as crianças mais velhas que tomaram conta dos bebês e os homens e as mães rejeitaram as filhas mulheres, o que comprometeu o desenvolvimento emocional delas. Marta fez essa relação explicitamente ao falar de sua irmá de quinze anos, que ficou internada em um Hospital Psiquiátrico por sofrer de anorexia e ter tentado suicídio. Disse ainda que foi ela quem criou a irmã e que os problemas da adolescente se deviam à rejeição paterna. Bruna foi criada por essa irmã de sua mãe e pela avó materna até os seis anos de idade e não tem contato com o pai. Há um ano a mãe havia conhecido José, de cinquenta anos, seu novo companheiro, engravidou e resolveu assumir os cuidados com a filha trazendo-a para morar consigo e o marido. A nova família assim constituída foi viver na casa que pertencia à família de origem do padrasto de Bruna, ou seja, os irmãos mais novos de José também moravam lá. 
Bruna estava insegura e confusa a respeito dos cuidados que recebia dos adultos: as pessoas que a criaram até então estavam gravemente doentes e o vínculo com sua mãe era novo e estava ameaçado pelo nascimento do irmão. Dormia na cama da mãe, acordava no meio da madrugada para comer, não tinha amigos na escola e chupava o dedo, mas, ao mesmo tempo, tinha excelente desempenho escolar. Marta trouxe o desejo de formar uma família e construir uma história diferente, mas questionava-se se isso seria possível, estava cansada, sua gravidez era de risco e parecia duvidar de suas competências enquanto mãe. Essas questóes puderam ser nomeadas durante a consulta.

A história de Bruna estava marcada por rompimentos de vínculos significativos e os sintomas que apresentava pareciam estar relacionados à trajetória familiar contada por sua máe; que merecia ser escutada e nomeada em um espaço conjunto ${ }^{4}$. Devido à proximidade do parto, foi possível realizar mais duas consultas com Bruna e sua mãe. José não compareceu e justificou sua ausência por motivo de trabalho. Assim, esta primeira etapa do processo terapêutico, envolvendo um total de três sessóes com mãe e filha, teve a duração de 15 dias, sendo interrompida pelo nascimento do irmão da menina. Marta referiu melhoras em Bruna após a primeira consulta, disse que a menina aceitara dormir no próprio quarto e estava se relacionando melhor com o padrasto. Bruna disse que gostaria que José fosse seu pai e que, após o nascimento do irmão, caberia a ela cuidar do bebê. Falou também que ficava em dúvida a respeito de quem deveria chamar de mãe: Marta ou a avó materna que a criou até então e insistia em ser chamada de mãe. Esse conflito reforça a hipótese de que Bruna estava reconstruindo ou construindo as figuras parentais e que os conteúdos transgeracionais permaneciam inquestionáveis: os pais abandonam seus filhos e são as crianças que cuidam dos bebês. Os desenhos feitos por Bruna durante as consultas foram estereotipados e encobertos - ela colou uma folha por cima do desenho e entregou à terapeuta dizendo que era um quadro e que, mesmo que estivesse coberto, era possível ver o que estava ali. As intervençóes buscaram tanto acolher a história da família, fortalecendo a função materna de Marta, quanto dar lugar às emoçôes de Bruna, nomeando sua insegurança, raiva e legitimando que ela ainda era criança e precisava de cuidados. Com isso, instaurava-se uma possibilidade criativa de quebrar a repetição geracional que colocava Bruna no lugar da criança/mãe, cuidadora do irmão menor, como sua mãe havia sido. As consultas ofereciam um espaço para restaurar o bom objeto, ou seja, estabelecer a maternagem de Marta por Bruna, e de pensar a dor, quando se questionavam os desígnios geracionais. Quando Joáo nasceu sofreu de parada cardiorrespiratória e precisou ficar internado. Nessa ocasiáo, Bruna foi para a casa de uma tia no interior. Foi um período de crise para a 
família: os sentimentos de medo, abandono e perda retornaram com toda a força. Marta manteve contato com a terapeuta por telefone e disse que estava dividida, preocupada com os dois filhos, pois temia pela vida do filho, e Bruna estava longe, sem que soubesse ao certo o que estava acontecendo.

Passado um mês e meio, a mãe compareceu para uma consulta com seus dois filhos. João dormiu o tempo todo e pareceu tranquilo aninhado no colo da mãe. Marta falou com mais segurança a respeito de suas competências enquanto mãe e reafirmou o desejo de constituir sua família e oferecer aos filhos cuidados parentais. Porém Bruna falou que o padrasto náo aceitava que ela o chamasse de pai. Marta tentou encobrir essa situação, negando o que a filha dizia, mas logo assumiu que as coisas eram como a menina contava e que o marido não estava conseguindo se relacionar com Bruna. Dessa maneira, retornaram os aspectos que apontam fragilidades presentes na constituição da família e que tocam questóes contemporâneas que interferem na parentalidade: o declínio da função patriarcal e a fragilização parental. A questão a ser trabalhada com essa família não era a de chamar ou não José de pai, mas a de pensar com eles opçóes para se relacionarem de forma mais satisfatória para todos. Assim, a terapeuta reafirmou a importância do comparecimento de José às sessões.

Aproveitando uma licença por questóes de saúde, José compareceu à sessão seguinte. Ele falou do medo que sentiu com o risco de morte do filho e da dificuldade em assumir uma função parental com Bruna. Emocionado, disse que era muito apegado aos seus pais e que ficou muito abalado com a morte deles há alguns anos. José falou que constituiu família mais tarde que as outras pessoas costumam fazer e que estava difícil adaptar-se a todas as mudanças que ocorreram nos últimos nove meses. Contou que conheceu Marta e em um mês estavam casados e ela grávida, atingindo desse modo o seu desejo de ser pai de um filho homem. José parecia querer resgatar a família de origem perdida, por isso tanto empenho num determinado tipo de parentalidade associada a aspectos transgeracionais, sem valorização do vínculo conjugal. Mostrou-se aturdido frente à realidade vivida totalmente diferente da fantasia idealizada, como demonstraram suas atitudes ao longo da consulta.

Quando seus sentimentos puderam ser expostos e compreendidos sem censura, ele se mostrou dividido, queria ocupar seu lugar de pai, mas ao mesmo tempo acreditava que esse espaço não era seu. No início, em contato com seus aspectos mais regressivos, coloca-se na posiçáo de filho assustado, enfraquecido e sem competência para exercer a paternidade, mesmo com seu filho biológico. Depois, se fortaleceu em sua identidade paterna, reconhecendo que mesmo não se sentindo à vontade de ser chamado de pai, ele estava ajudando a mulher nos 
cuidados com Bruna, por exemplo quando aconselhava Marta a respeito de como educar as crianças; ou quando decorava o quarto de Bruna e se preocupava com o bem-estar dela.

Mesmo diante das fragilidades dos vínculos nessa família, foi possível perceber mudanças na posição que cada um ocupava. A mãe estava mais confiante e fortalecida em sua função materna. Bruna estava mais tranquila permanecendo no lugar de filha/criança, deixando-se cuidar por sua mãe e pedindo os cuidados de um pai. João estava se desenvolvendo bem e tanto seus pais quanto sua irmá atribuíam sentido às suas açóes, subjetivando-o.

Esta segunda etapa do atendimento teve a duração de dois meses, pois João foi internado por não defecar, havia suspeita de megacólom e possibilidade de cirurgia. Diante da delicada situação clínica de João, Bruna retornou à casa de parentes a fim de que Marta dispusesse de mais tempo para cuidar do filho. Mais uma vez a família se deparava com a fragilidade de sua constituição. Apesar da necessidade de darem prosseguimento às consultas, optaram por interromper o atendimento. Como da primeira vez, a mãe seguiu em contato telefônico com a terapeuta para dar notícias. Fazia isso especialmente no horário que seria a consulta da família e falava do quanto estava se sentindo sobrecarregada e preocupada com os dois filhos, sentindo-se incapaz de cuidar dos dois ao mesmo tempo. Após três meses, Marta pediu para retornar aos atendimentos, pois Bruna havia piorado. Essa piora se referia a manifestaçóes claras de insegurança e não de comer compulsivamente.

A terceira etapa do tratamento se configurou como uma terapia familiar, mas sem a presença de José, que justificava sua ausência em função do emprego. A proposta do novo setting terapêutico se deu mediante a demanda de Marta e também das crianças, que preenchiam as sessóes com conteúdos geracionais e das dinâmicas vinculares da família atual, cada vez mais distanciados do sintoma emergente de Bruna. João seguia com problemas de saúde e Bruna mostrava-se ressentida de ir para a casa da tia cada vez que o irmão ficava doente. Marta disse que ficava dividida entre os dois filhos e agora estava pensando em voltar para a casa de sua mãe com as crianças, pois morava na casa da família de origem do marido e a convivência com os cunhados estava insustentável: eles exigiam que Bruna e João ficassem dentro do quarto, sem fazer barulho e José não intercedia para defendê-los. Novamente aqui é possível observar a fragilidade da estrutura familiar construída. José relutava para se desprender do lugar de filho, deixando Marta e as crianças sem a segurança de que necessitavam. No dia e horário da consulta seguinte, Marta entrou em contato com a terapeuta para avisar que não seria possível comparecer à consulta, pois, de fato, havia saído de casa e estava no 
interior. Uma semana depois, a mãe e os filhos voltaram para casa: José havia feito uma reforma que garantia a privacidade da família e o lugar das crianças na casa.

Essas experiências de ruptura e fragmentação marcavam a vida de Bruna e dificultavam para que ela estabelecesse padróes de apego seguro (Bowlby, 1969/2002). Era frequente que precisasse ir às pressas para a casa de algum parente no interior e ficasse longe da mãe, do irmão, da escola e do tratamento - espaço que ela sempre demonstrou ser importante e proveitoso para ela. A experiência de fragilidade e ruptura se manifestaram contratransferencialmente e a analista passou a sentir essa experiência em sua própria pele. Mesmo que as ausências fossem justificadas, era difícil manter a continuidade da terapia aprofundando os conteúdos, pois, com as interrupçóes, as situaçôes trazidas eram colocadas sempre como emergências, momentos de crise a serem resolvidos às pressas. Dar-se conta da situação, por meio de identificação projetiva, manifesta contratransferencialmente, ajudou a terapeuta a rever sua posição perante o atendimento dessa família. Provavelmente, esse era o padrão que adotavam para se relacionar em outros contextos e era preciso trazer esse tema para ser discutido.

Abordadas as rupturas e fragilidades que existiam no transcorrer do próprio processo terapêutico, deslocando a temática para o aqui-agora das sessóes, foi possível nomear a ameaça de abandono que estava sempre presente na relação de mãe e filha, o que prejudicava a construção de um sentimento de confiança. Quando Marta saía sozinha, Bruna chorava e ligava para a mãe, mais de dez vezes, para se certificar de que ela voltaria para casa. Nas sessóes, a mãe demonstrava esgotamento por se sentir extremamente solicitada. Não suportava quando a filha manifestava desagrado com alguma situaçáo e isso reforçava seu sentimento de incompetência. Essa dinâmica ia ao encontro do esforço que a menina fazia por manter suas angústias encobertas e das inúmeras reparaçóes precoces que fizera no inicio do processo. É possível retomarmos aqui o estudo de Miranda (2010) em que o comer compulsivo é entendido como tentativa de restaurar o bom objeto.

No decorrer dos encontros, a terapeuta manteve intervenções que acolhiam o sofrimento familiar e fortaleciam tanto a função materna quanto a possibilidade de apego seguro. Por exemplo, quando a mãe disse que estava sem saber o que fazer desde que a filha passou a cobrá-la para conhecer o pai biológico, a terapeuta interpreta o fato de a menina estar se sentindo mais segura em tocar nesse assunto porque estava mais confiante a respeito de seus cuidadores, e que era compreensível que Bruna quisesse saber mais sobre sua origem. Ao longo do processo, a mãe foi se apropriando da função parental e as crianças se beneficiaram desse espaço na medida em que podiam expressar seus estados emocionais e confiar que estes seriam contidos na mente da terapeuta e, posteriormente, na da mãe. Além disso, 
experimentar a constância do espaço terapêutico foi um primeiro estágio para que a menina se sentisse segura e confiante em relação à sua mãe - passando de um padrão de apego predominantemente ansioso para outro mais seguro. Assim, após a analista dar-se conta dos elementos de identificação projetiva (Aguayo, 2011; O'Shaughnessy, 1990) e elucidar isso com todos, o atendimento seguiu por mais oito meses, sem interrupções, até que a mãe voltou a trabalhar em período integral e não pôde dar continuidade à terapia.

Dois anos depois, Marta procurou a terapeuta solicitando a retomada dos atendimentos. Estava enfrentando uma crise conjugal e acreditava que o marido estivesse deprimido. Além disso, estava se sentindo sozinha, pois José não participava dos cuidados com as crianças. Assim, a demanda de Marta era a de incluir José na parentalidade e conjugalidade. Quando a família compareceu no atendimento seguinte, a necessidade de terapia familiar foi reafirmada por José e pelas crianças e o atendimento pôde ser reiniciado.

\section{Possibilidades interpretativas}

A partir do caso relatado é possível pensar que o sintoma de comer compulsivamente manifesto por Bruna estava relacionado à fragilização das figuras parentais. $\mathrm{O}$ que está em ressonância com os estudos sobre obesidade e comer compulsivo citados na introdução. A oferta de atendimento no contexto da clínica da parentalidade foi feita com base nos conteúdos geracionais trazidos pela mãe na primeira consulta. Marta manifesta tanto o medo da repetição de uma história quanto a angústia por se sentir enfraquecida em sua função materna. Da mesma maneira, Bruna, a filha, faz um pedido quando entrega seu desenho à terapeuta dizendo que ela era capaz de ver o que havia ali, mesmo que estivesse encoberto. A menina tinha uma demanda por esclarecer aquilo que "estava encoberto", conteúdos da herança transgeracional, talvez, e via na terapeuta uma figura que poderia ajudar nesse processo.

Os cônjuges apresentavam dificuldades pare exercer a parentalidade, ou seja, oferecer proteção, segurança, apego e compreensão dos estados emocionais das crianças, pois ainda necessitavam elaborar suas próprias histórias, presos que estavam aos lugares de filhos. Nesta família, tudo acontecia de repente, sem tempo para que as emoçóes pudessem emergir, serem reconhecidas, nomeadas e elaboradas. Quando Bruna expressava qualquer sentimento para a mãe ou padrasto, eles ficavam angustiados e acabavam por brigar com a menina. Dessa forma, comer compulsivamente também pode ser entendido como metáfora do sintoma 
familiar, em que as emoçóes invadem aleatoriamente, sem nomeação e os excessos permanecem no corpo (obesidade).

A mãe não confiava em suas competências e se sentia culpada por não ter criado a filha até os seis anos de idade, o que interferia na segurança necessária para exercício de sua função parental. Nos momentos em que precisava agir com autoridade, não era consistente com Bruna e as duas acabavam por manter uma relação fraternal (Zanetti \& Gomes, 2009). Evidenciar essa situação para a família, descrevendo cenas que ocorriam na própria consulta, fez com que a mãe passasse a suportar mais os momentos de raiva que Bruna manifestava. A menina, por sua vez, pôde ensaiar momentos de expressão de raiva e tristeza, sem sentir que estava destruindo sua mãe. Por alguns meses, essa foi a dose de emoção possível de ser suportada e a temática das consultas permaneceu nesse assunto. Porém criar um espaço no qual a emoção pudesse surgir, ser sentida, nomeada e processada ajudou para que a mãe fortalecesse sua função parental e para que as crianças recebessem os cuidados de que precisavam. Gutfreind (2009) chama a atenção para o fato de que nas histórias entre pais e filhos é preciso aceitar a lentidão e ser redundante, contando e voltando a contar, com a paciência de quem constrói alguma segurança na repetição de uma história.

Como foi descrito no estudo de Mishima e Barbieri (2009), Bruna apresentava sentimento de baixa autoestima, insegurança e sentimento de solidáo; mas não demonstrou comportamento de passividade, nem dificuldades no processo criativo - o que pode ter contribuído para a remissão do sintoma de comer compulsivo no segundo mês de terapia. Quando o padrasto de Bruna compareceu a uma consulta, confirmou-se a hipótese de que o casal não havia estabelecido uma conjugalidade consistente e estava unido precocemente pelo fato de serem pais de um bebê. Para José, o importante era ser pai, não marido. Porém, como foi dito, se tornar pai é um processo que vai além de fatores biológicos (Solis-Ponton \& Lebovici, 2004) e José não estava seguro no exercício de sua função parental. Sempre que a mãe manifestava o desejo de formar uma família, deixava subentendido que considerava ainda não a ter constituído.

No decorrer das consultas, foi possível perceber que esse sentimento da mãe era incrementado pela decepção que sentiu ao perceber que o novo parceiro não era como ela gostaria que fosse, especialmente no que se referia a Bruna, pois ela queria oferecer um novo pai para sua filha, já que o pai biológico a havia abandonado. Segundo Gomes e Levy (2010), quando o sujeito nega sua história anterior na tentativa de evitar a dor decorrente da perda das ilusóes e idealiza a nova relação aumenta a possibilidade de repetição. José apresentava dificuldade em adotar Bruna, pois dizia que ela tinha um pai e se ele assumisse os cuidados 
com a menina estaria traindo o seu próprio pai - mais uma vez os conteúdos das histórias passadas se misturavam com a história atual e dificultavam o estabelecimento das novas relaçóes (Gutfreind, 2009). Porém as dificuldades de José se estendiam a João e quando a família reiniciou o processo terapêutico, desta vez caracterizado como terapia familiar, estava às voltas com o declínio específico da função do pai (Gomes \& Levi, 2009).

Em um vídeo chamado "Éléments de la psychopathologie du bébé” (1998), Lebovici e Chiland discutem a eficácia das consultas terapêuticas que abordam a questão da parentalidade e afirmam que a consulta pode tanto fazer o sintoma desaparecer e a família ficar bem, quanto viabilizar uma psicoterapia. No caso relatado, o sintoma do comer compulsivo de Bruna desapareceu, mas a família entrou em contato com a fragilidade de seus vínculos, o que a fez demandar um processo de terapia familiar.

\section{Consideraçóes finais}

Por ser considerado um problema de saúde pública, cada vez mais os serviços que prestam atenção às crianças devem estar preparados para tratar queixas de obesidade e comer compulsivo. Este estudo foi feito no contexto da saúde pública e indica que trabalhar no modelo da clínica da parentalidade pode contribuir para o tratamento da obesidade infantil e, portanto, pode integrar a rede de cuidados ${ }^{5}$ para esses casos.

O sintoma expresso pela criança denunciava não apenas o conflito da menina, mas também o da sua família. Com isso, não se pretende afirmar que todos os conflitos infantis são decorrentes de questóes parentais, mas que, ao longo das entrevistas iniciais, o profissional deve se perguntar a serviço de que está o sintoma da criança e o que isso significa para a família. Muitas vezes, o sofrimento infantil é só a ponta do iceberg e para que uma mudança de fato ocorra é necessário incluir todo o grupo familiar. Vale ressaltar ainda a complexidade dos vínculos nas famílias reconstituídas e a influência do legado geracional, principalmente dos conteúdos transgeracionais, que podem ser determinantes no favorecimento do exercício parental. Bruna, seguindo em acompanhamento médico e nutricional, além da terapia de família, em um ano teve uma redução de peso significativa. A terapia familiar contribuiu para que o controle alimentar prescrito pela nutricionista não fosse tomado em um registro de ataque e privação. Ou seja, a mãe percebeu que negar um doce para a filha era um cuidado que estava dedicando a ela, e a menina por sua vez pôde entender o significado desse não, na medida em que pôde ter supridas faltas emocionais básicas. 
No caso relatado, a clínica da parentalidade contribuiu para o desaparecimento do comer compulsivo e para que a demanda de terapia familiar pudesse ser formulada pelos próprios membros da família. A demanda ainda é escassa nos serviços e instituições públicas de saúde que se propóem a tratar de crianças.

\section{Referências}

Aguayo, J. (2011). The role of the patient's remembered history and unconscious past in the evolution of Betty Joseph's "here and now" clinical technique (1959-1989). The International Journal of Psychoanalysis, 92, 1117-1136.

Bion, W. R. (1966). O aprender com a experiência. In W. R. Bion. Os elementos da psicanálise (pp. 7-117). Rio de Janeiro: Zahar. (Trabalho originalmente publicado em 1962).

Bowlby, J. (2002). Apego - A natureza do vínculo. São Paulo: Martins Fontes. (Trabalho original publicado em 1969).

Casanova, A., Saladin, M., \& Lebovici, S. (1998). Éléments de la psychopatologie du bébé [Filme-vídeo]. A. Casanova, \& M. Saladin, realização. S. Lebovici, dir. Paris. 1 DVD, 90 min. color. son.

Corso, D., \& Corso, M. (2009). Prefácio. In C. Gutfreind (Ed.). Narrar, ser pai, ser mãe \& outros ensaios sobre a parentalidade (pp. 9-16). Rio de Janeiro: Bertrand.

Da Silva, M. C. P. (2011). A construção da parentalidade em máes adolescentes: um modelo de prevenção e intervenção. Curitiba: Honoris Causa.

Gomes, I. C., \& Levy, L. (2009). O mal-estar e a complexidade da parentalidade contemporânea. Cadernos de Psicanálise - SPCRJ, 23(28), 217-238.

Gomes, I. C, \& Levy, L. (2010). Casamentos e recasamentos: diferentes tempos de um encontro amoroso. Cadernos de Psicanálise - SPCRJ, 26(29), 19-34.

Gutfreind, C. (2009). Narrar, ser pai, ser mäe \& outros ensaios sobre a parentalidade. Rio de Janeiro: Bertrand.

Kaës, R. (2011). Um singular plural. Rio de Janeiro: Ediçôes Loyola.

Lebovici, S. (1987). O bebê, a mãe e o psicanalista. (C. E. Reis, Trad.). Porto Alegre: Artes Médicas. (Original publicado em 1983).

Miranda, M. R. (2010). A complexidade da relação mãe-filha nas patologias dos contrários. In C. A. N. B. Bruno (Ed.). Distúrbios alimentares: uma contribuição da psicanálise (pp. 123-154). Rio de Janeiro: Imago.

Mishima, F. K. T., \& Barbieri, V. (2009). O brincar criativo e a obesidade infantil. Estudos de Psicologia, 14(3). Recuperado em 3 de agosto, 2013, de

$<$ http://www.scielo.br/scielo.php?script=sci_arttext\&pid=S1413-294X2009000300009\&lng $=$ en\&nrm=iso\&tlng=en>.

Psic. Clin., Rio de Janeiro, vol. 26, N.2, P. I05 - I I9, 2014 
OMS - Organización Mundial de la Salud. (2013). Sobrepeso y obesidad infantiles. Recuperado em 2 de agosto, 2013, de <http://www.who.int/dietphysicalactivity/childhood/es/index. html>.

O’Shaughnessy, E. (1990). A teoria do pensar de W. R. Bion e novas técnicas em análises de crianças. In Melanie Klein hoje - Desenvolvimento da teoria e da técnica (pp. 196-210) v. 2. Rio de Janeiro: Imago.

Solis-Ponton, L., \& Gutfreind, C. (2004). A transmissão transgeracional na consulta terapêutica da parentalidade. In M. C. P. Da Silva \& L. Solis-Ponton (Eds.). Ser pai, ser mãe - parentalidade: um desafio para o terceiro milênio (pp. 77-88). São Paulo, SP: Casa do Psicólogo.

Solis-Ponton, L., \& Lebovici, S. (2004). Diálogo Letícia Solis-Ponton e Serge Lebovici. In M. C. P. Da Silva e L. Solis-Ponton (Eds.). Ser pai, ser mäe - parentalidade: um desafio para o terceiro milênio (pp.21-27). São Paulo, SP: Casa do Psicólogo.

Zanetti, S. A. S., \& Gomes, I. C. (2009). A ausência do princípio de autoridade na família contemporânea brasileira. Psico - Pucrs, 40(2), 194-201.

Winnicott, D. W. (1971). Therapeutic consultations in child psychiatry. Londres: Hogarth Press and Inst. of Psychoanalysis.

Winnicott, D. W. (1999). Dizer não. In C. Winnicott et al.. Conversando com os pais. São Paulo: Martins Fontes (Trabalho original publicado em 1960).

\section{Notas}

${ }^{1}$ Este artigo foi financiado por Fundação de Amparo a Pesquisa do Estado de Sáo Paulo - FAPESP.

${ }^{2}$ Todos os nomes aqui mencionados são fictícios.

${ }^{3}$ Consulta Terapêutica (Winnicott, 1971; Lebovici, 1983/1987).

${ }^{4} \mathrm{O}$ Serviço em que o atendimento se deu oferecia apenas o tratamento de psicoterapia infantil. ${ }^{5} \mathrm{O}$ termo rede de cuidados é aqui empregado para designar os diversos profissionais e especialidades que podem se ocupar simultaneamente do tratamento de uma criança obesa.

Recebido em 01 de dezembro de 2012 Aceito para publicação em 12 de dezembro de 2013 